VI Congresso Brasileiro de Informática na Educação (CBIE 2017)

Anais do XXIII Workshop de Informática na Escola (WIE 2017)

\title{
Desafio de Programação para Meninas do Ensino Médio: Um Relato de Experiência
}

\section{Cristina Paludo Santos, Denilson Rodrigues da Silva, Maria Gisele Flores da Silveira, Giana Ferreira}

Universidade Regional Integrada do Alto Uruguai e das Missões (URI)

98.802-470 - Santo Ângelo - RS - Brasil

paludo@san.uri.br,deniro@san.uri.br,_guiga.flores.silveira@hotmail.com, giana.ferreira.s@gmail.com

\begin{abstract}
This paper describes, in general terms, an experience realized with high school girls that aims to bring them closer to the area of computing. To attract the interest of the young audience, the established focus is the creation of applications for the Android platform. The methodology applied and the results obtained are shared with the academic community through the present article so that the experience can be improved and replicated.
\end{abstract}

Resumo. Este artigo descreve, em linhas gerais, uma experiência realizada com alunas do ensino médio cujo o objetivo é aproxima-las da área de computação e do processo de desenvolvimento de tecnologia. Para atrair o interesse do público jovem, o Desafio de Programação foi desenvolvido em torno da criação de aplicativos para a plataforma Android. A metodologia aplicada e os resultados obtidos são compartilhados com a comunidade acadêmica por meio do presente artigo de modo que a experiência possa ser aprimorada e replicada.

\section{Introdução}

Os debates e as estratégias que se desenvolvem em prol da democratização do saber e do acesso das meninas/mulheres nas áreas científica e tecnológica visam quebrar estigmas e atingir o equilíbrio entre os gêneros nesses ambientes. Historicamente, a participação feminina no progresso científico e tecnológico foi pautada em muitas dificuldades e preconceitos. $\mathrm{O}$ acesso desigual à educação, os conceitos pré-estabelecidos relacionados a incapacidade intelectual das mulheres para entender as ciências mais abstratas e os estereótipos culturais foram alguns dos fatores que contribuíram para o afastamento das mulheres do universo científico e tecnológico.

Embora várias conquistas negam qualquer discurso que desmereça a capacidade feminina e prova que as mulheres cientistas não faltam na História, ainda no século XXI a herança de determinados conceitos influencia tanto nas ações das mulheres quanto nos julgamentos sofridos por elas. Isto se estabelece em vários contextos da ciência, inclusive no universo da Ciência da Computação, que não se configura como uma exceção nesta esfera (Lima, 2013).

Este cenário tem impulsionado iniciativas que fazem uso de diferentes abordagens, mas que convergem em seus objetivos. Neste sentido, tanto o ensino de Computação nas escolas a fim de disseminar o pensamento computacional, quanto o 
fomento por uma maior inclusão das mulheres no segmento de TI têm sido uma preocupação crescente (Barcelos, 2012) (Santos, 2016) (Gomes, 2014) (Maciel, 2016).

O presente artigo apresenta uma experiência que insere-se no elenco de iniciativas em prol da ampliação da imagem mental dos jovens sobre o que significa ser um(a) cientista da computação. A partir da experiência, denominada "Desafio de Programação para Meninas", pretende-se estimular meninas do ensino médio a considerarem as carreiras de computação como opções atrativas para seu futuro, consolidar a imagem de que os espaços de Ciência e Tecnologia são também lugares onde as mulheres podem e devem ocupar e, também, contribuir para a disseminação de práticas educativas que empreguem o ensino de Computação na educação básica.

Alinhado a outras iniciativas exploradas na literatura (De França, 2013) (Gomes, 2014) (Ramos, 2015) o desafio direcionou esforços em torno dos conceitos e práticas de programação, visto que a programação perpassa todas as áreas do conhecimento e norteia o desenvolvimento de diversas habilidades cognitivas do educando, a citar: criatividade, raciocínio lógico, resolução de problemas, criticidade, reflexão, interpretação, concentração, pensamento algorítmico e computacional, dentre outras. Acredita-se que essas habilidades desenvolvidas a partir do estudo da programação são de grande valia para a formação de um sujeito crítico e consciente, que poderá contribuir de forma significativa no processo de transformação da sociedade.

Uma descrição mais detalhada sobre as ações que envolveram o Desafio de Programação para Meninas é apresentada nas seções subsequentes. Na seção 2 é apresentada a metodologia empregada na execução do projeto. Na seção 3 são descritos os resultados alcançados e, na seção 4 são apresentadas as considerações finais e direcionamentos futuros.

\section{Metodologia}

O Desafio de Programação para Meninas compreende um conjunto de atividades que visam evidenciar o potencial criativo, a competência, a inteligência e as habilidades que as meninas possuem para produzir tecnologias e não apenas para utiliza-las. As atividades incluem a promoção de discussões a respeito dos benefícios providos pela tecnologia para a sociedade, reflexões sobre a importância do papel da mulher nesse universo e geração de conhecimentos teóricos, práticos e operacionais. A Figura 1 apresenta as principais atividades relacionadas ao Desafio.

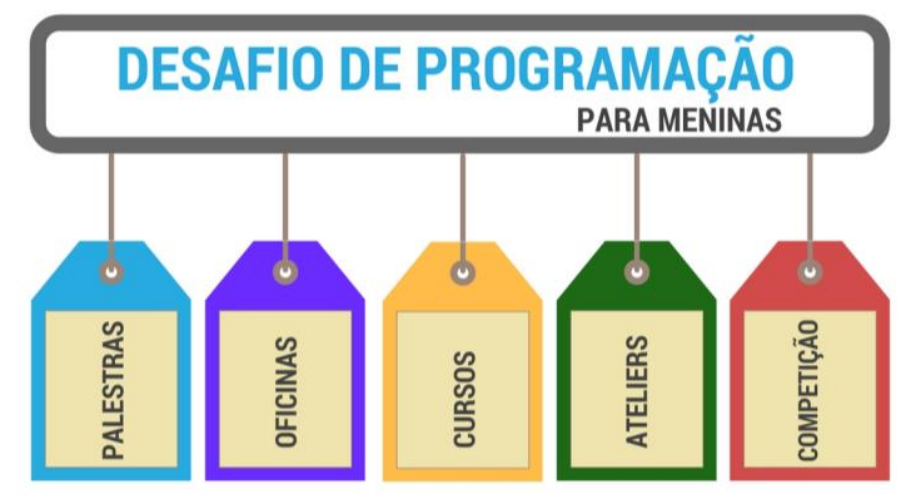

Figura 1. Atividades que compõem o Desafio de Programação 
VI Congresso Brasileiro de Informática na Educação (CBIE 2017)

Anais do XXIII Workshop de Informática na Escola (WIE 2017)

O projeto foi executado na instituição proponente e contou com a participação de 54 meninas, do ensino médio, provenientes de escolas públicas e privadas do município. As meninas compunham 13 equipes, sendo que cada equipe contava com um professor da escola como responsável. Adicionalmente, atuaram no projeto 2 docentes da computação e 2 acadêmicas dos cursos de bacharelado em Ciência da Computação e Sistemas de Informação.

Para obter informações sobre os diferentes matizes das meninas participantes em relação à área de computação elaborou-se um questionário contemplando questões que permitem identificar o perfil do público-alvo, seu comportamento em relação ao uso da tecnologia, seu conhecimento em relação a área de computação e o interesse do público em relação a cursos relacionados com a área de computação. Tais questionários foram respondidos no momento da inscrição das participantes. Os resultados obtidos a partir deste mapeamento serviram como base para elaboração do material didático do curso respeitando-se principalmente o conhecimento e interesse das alunas e, também, foram utilizados ao término das atividades que envolvem o Desafio de Programação como parâmetros para mensurar o quanto a experiência vivenciada pelas meninas modificou a sua visão em relação a algumas questões relacionadas à área.

A primeira atividade do Desafio de Programação consistiu na promoção de um evento cuja programação contou com diversas palestras incluindo temas como o panorama sobre a participação das mulheres na área científica e tecnológica; projetos que visam estimular meninas para a área tecnológica; habilidades adquiridas por acadêmicos dos cursos de Ciência da Computação e Sistemas de Informação; dentre outros. Como parte das atividades também foram promovidas oficinas de pitch, brainstorming e utilização de Canvas para elucidação de ideias.

Um pitch caracteriza-se como uma apresentação rápida de uma ideia/projeto, utilizado para gerar interesse das pessoas e atrair os recursos necessários para concretizala. Através desta prática, os participantes exercem a arte de vender suas ideias, aprimoram a capacidade de comunicação em público, desenvolvem habilidades de improvisação, essencial para o momento de perguntas e respostas, dentre outros. Já, o brainstorming é uma técnica de inovação e geração de ideias em conjunto. O importante desta técnica é a reunião de pessoas diferentes e essa pluralidade faz com que soluções inovadoras e simples, ao mesmo tempo, emerjam e sejam colocadas em prática com maior facilidade.

Após a realização do evento, iniciaram-se as atividades referentes ao curso de programação. As alunas, que nunca tiveram contato com conceitos e práticas de programação, participaram de aulas de desenvolvimento de aplicativos móveis para Android utilizando a plataforma de programação visual APP Inventor - uma ferramenta idealizada pelo Instituto de Tecnologia de Massachusetts (MIT), dos Estados Unidos em parceira com o Google, que contempla uma metodologia natural, fácil para aprender e que simplifica a parte de código mantendo a parte lógica. O curso teve duração de 8 semanas com carga horária total de 32 horas/aula.

O material didático foi planejado e desenvolvido respeitando-se o conhecimento prévio das alunas. Inicialmente foram abordados conceitos introdutórios de algoritmos e programação e, somente após a assimilação destes conceitos pelas alunas fez uso da 
ferramenta App Inventor. Para cada conceito abordado foi atribuído um exemplo de sua utilização em situações cotidianas. Além disso, os conteúdos algorítmicos foram testados na prática pelas meninas. Os detalhes sobre a aplicação foram deixados livres na tentativa de estimular o pensamento criativo.

Em seguida, as alunas reuniram-se em equipes com o objetivo de desenvolverem todo o processo de criação de um aplicativo, desde a concepção da ideia e planejamento do aplicativo até a implementação e apresentação do resultado final. $\mathrm{O}$ uso das técnicas de Canvas, pitch e brainstorming foi solicitado na execução das atividades. Nesta etapa as alunas contaram com o apoio das 2 acadêmicas da área de tecnologia que atuaram como guias e modelos de conduta ao longo do desenvolvimento do aplicativo. A Figura 2 apresenta registros fotográficos da participação das meninas em tais atividades.
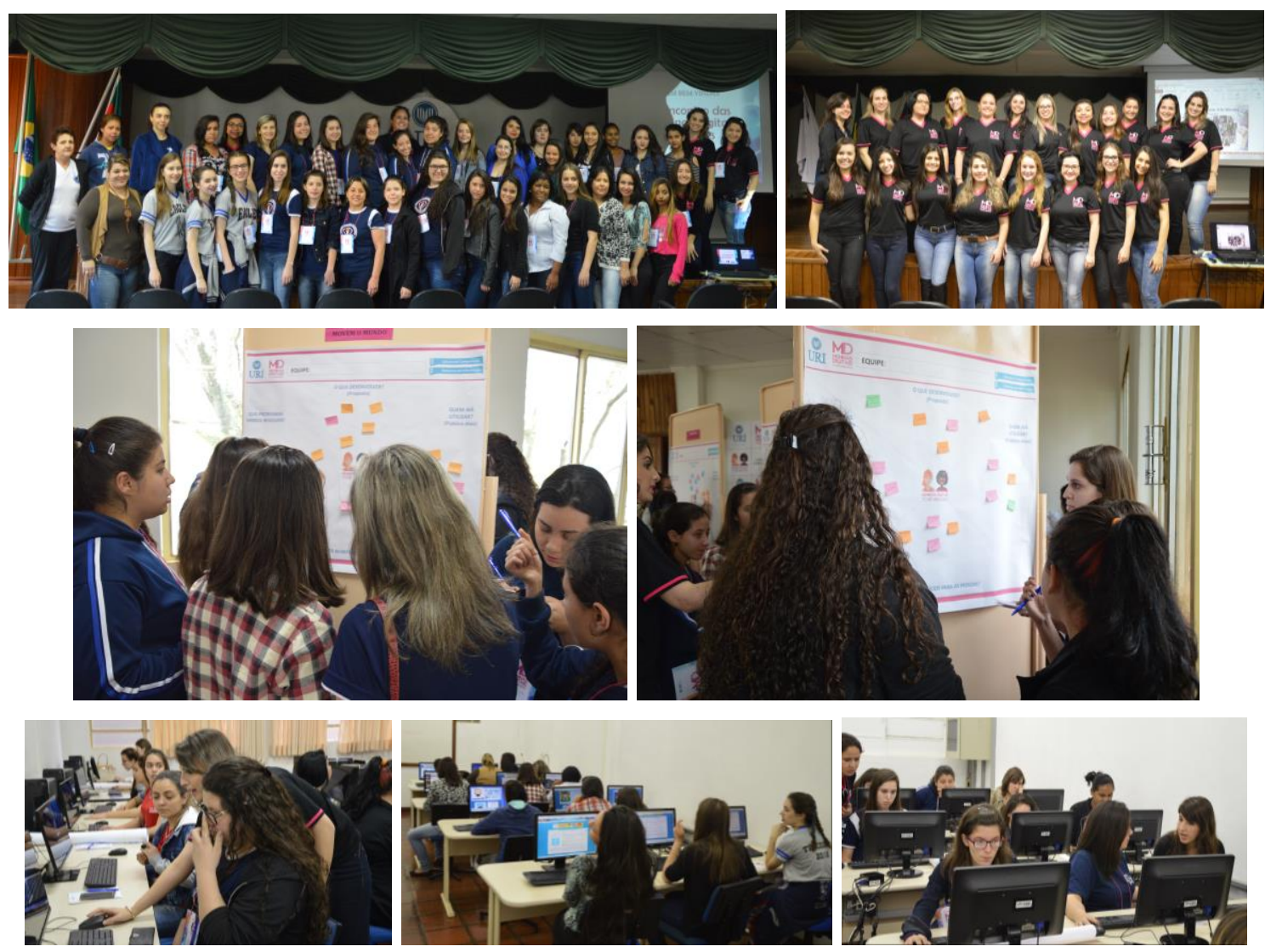

Figura 2. Meninas participantes do curso e atelier de programação

Em paralelo ao curso também foi promovido o atelier de programação que se constituiu como um espaço descontraído para explorar ideias, trocar experiências e conhecimentos relacionados aos aspectos de programação, usabilidade, design de interação e experiência do usuário. $\mathrm{O}$ atelier foi promovido semanalmente de forma presencial nos laboratórios da Universidade.

Após o término dessas atividades um novo questionário foi aplicado e respondido por todas as participantes. O intuito é verificar o nível de absorção dos conceitos e dificuldades encontradas, além de avaliar o quanto houveram modificações nas percepções das meninas em relação a área de computação. 
VI Congresso Brasileiro de Informática na Educação (CBIE 2017)

Anais do XXIII Workshop de Informática na Escola (WIE 2017)

\section{Resultados}

Após findadas as etapas descritas na Seção 2 deste artigo e uma vez adquiridas as habilidades necessárias para criação de um aplicativo, as meninas participantes foram desafiadas a participar de uma competição que buscou fomentar o interesse das jovens pela aplicação dos conhecimentos obtidos com vistas à criação de algo que fosse socialmente útil e pessoalmente gratificante. Para tanto foram três meses intensos de trabalho em que as equipes construíram um plano de negócios, desenvolveram um aplicativo para um problema social e um pitch para apresentar a ideia. A proposta da competição foi "conceber um aplicativo voltado para a melhoria da qualidade de vida das pessoas". Participaram 5 equipes totalizando 25 meninas.

Os aplicativos desenvolvidos contemplaram os seguintes domínios de aplicação: (a) Orientações sobre a prática de exercícios físicos em academias ao ar livre; (b) Agenda diária para auxiliar os cuidadores de idosos; (c) Melhores ofertas nos supermercados da cidade; (d) Etiquetas sustentáveis para auxiliar a coleta seletiva de lixo e incentivar o uso de transporte coletivo e, (e) Biblioteca Virtual para agilizar o empréstimo de livros nas escolas. A Figura 3 apresenta a interface principal dos aplicativos desenvolvidos.
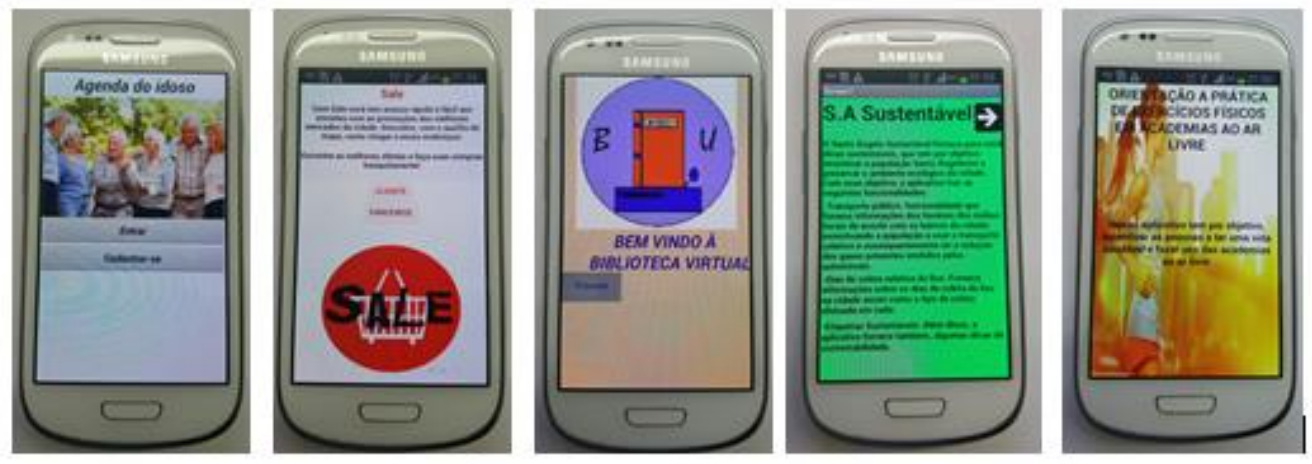

Figura 3. Aplicativos desenvolvidos pelas equipes participantes

A competição culminou em uma cerimônia de premiação e encerramento, onde as equipes dos 3 melhores aplicativos foram premiadas com troféus e medalhas (Figura 4).
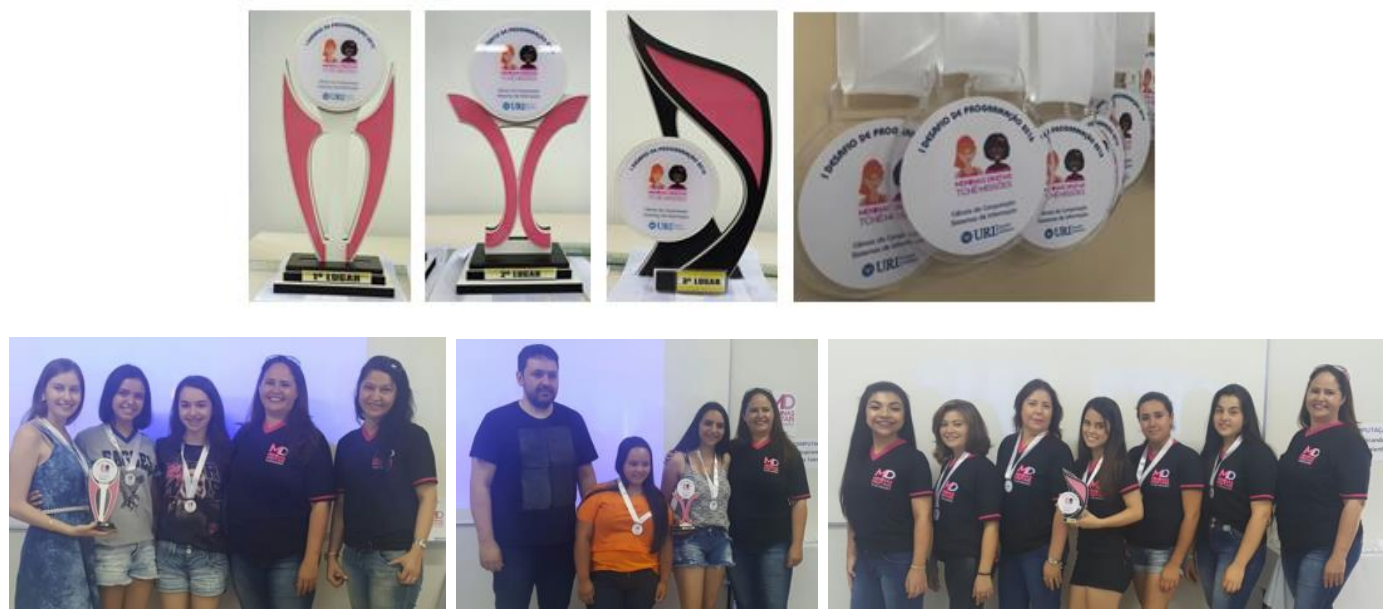

Figura 4. Troféus e medalhas da competição e equipes vencedoras 
VI Congresso Brasileiro de Informática na Educação (CBIE 2017)

Anais do XXIII Workshop de Informática na Escola (WIE 2017)

A seleção dos melhores aplicativos foi realizada por uma comissão de avaliação. Os critérios considerados no processo avaliativo foram: usabilidade ( $O$ aplicativo proposto é de fácil utilização?); originalidade (O aplicativo proposto promove contribuições para a melhoria de qualidade de vida do público para o qual foi projetado?); design gráfico ( $\mathrm{O}$ aplicativo proposto possui uma interface visual bem elaborada?); funcionalidade $(\mathrm{O}$ aplicativo apresenta funcionalidades suficientes para executar o que foi proposto?) e, apresentação da ideia (O pitch desenvolvido apresenta de forma clara os objetivos do aplicativo e o público para qual se destina?)

Além dos aplicativos desenvolvidos, outros resultados foram obtidos a partir de uma análise qualitativa realizada à luz da interpretação de especialistas em tecnologia educacional a partir das respostas dos questionários aplicados no início e no término das atividades. As análises geradas abarcam aspectos de comportamento em relação ao uso de tecnologias, interesse pela área de computação e, experiência do usuário em relação as atividades propostas

Em relação ao uso de tecnologias todas as participantes alegam utilizar ferramentas computacionais para elaboração de trabalhos escolares. As ferramentas mais citadas foram planilhas eletrônicas, editores de texto, internet e editores de vídeo. Ao findar o curso $96 \%$ afirmam que utilizarão os conhecimentos obtidos e relacionados à programação para desenvolvimento de trabalhos em várias disciplinas, alegando que o uso "vai ser um diferencial dos meus trabalhos em relação a outros". Isto demonstra que os conteúdos abordados foram assimilados de forma satisfatória e que os conhecimentos construídos em Computação, junto com suas tecnologias, implicarão em um melhor desenvolvimento do seu trabalho, na busca e construção de soluções em outros contextos. Apenas $4 \%$ das meninas alegam ter apresentado dificuldades na resolução dos desafios propostos, mas destacam que a utilização do ambiente foi um instrumento interessante e favorecedor da aprendizagem.

No levantamento inicial realizado, as meninas foram arguidas sobre sua área favorita sendo que $32 \%$ das meninas apontaram exatas, $28 \%$ biológicas e $40 \%$ humanas. Das meninas que preferem a área de exatas apenas 1 delas afirmou ter interesse em realizar um curso superior na área de tecnologia. Para as demais, ciência de computação ou quaisquer outros cursos ligados à área não era uma opção de curso. Após a realização do Desafio de Programação, 63\% das estudantes declararam um acréscimo de interesse pela área de Computação passando a cogitar a possibilidade de cursar computação, mas como segunda opção.

Todas as meninas participantes do projeto foram indagadas se já haviam tido contato ou sido incentivadas a programar antes de ingressar no Desafio. Dentre as declarações destacam-se: "Nunca. Eu nunca tive uma oportunidade dessas, mas estou amando tudo que estou aprendendo." (B.B, 16 anos); “Apenas coisas básicas de blogs. Nunca havia me aprofundado nesse assunto." (J.W, 17 anos); "Não. Está sendo uma experiência incrível." (R.X, 17 anos); "Não. Me chamou atenção justamente por isso." (R. G. $A, 18$ anos). A partir destas declarações percebe-se que há interesse das meninas pela área tecnológica, o que falta são iniciativas que oportunizem o contato das mesmas com este universo. 
VI Congresso Brasileiro de Informática na Educação (CBIE 2017)

Anais do XXIII Workshop de Informática na Escola (WIE 2017)

Grande parte das meninas (75\%) indicam ter apenas uma noção sobre as competências e habilidades de um profissional de computação. Além disso, $96 \%$ não sabiam como funcionava um programa de computador, mas se mostraram motivadas para aprender a programar um. Das meninas participantes $85 \%$ afirmam que gostaria de participar de outras edições ou cursos para aprender mais sobre computação. Estes dados demonstram uma discrepância em relação ao interesse das meninas em aprender mais sobre computação e o interesse em realizar um curso superior na área. Arguidas sobre os motivos que as levam a não pensar na computação como uma possibilidade de profissão futura obteve-se os seguintes resultados: $32 \%$ relacionam a área com o público masculino, $25 \%$ não sabem exatamente o que é ensinado nos cursos da área, $45 \%$ veem a computação como uma área difícil que envolve muita matemática.

Os resultados acima demonstram que ações como esta que foram propostas são valiosas para esclarecer muitas dúvidas que ainda pairam sobre a área de computação. Além disso, acredita-se que os resultados deste tipo de iniciativa possa surtir efeitos favoráveis no que se refere ao aumento do número de meninas na área a médio e longo prazo.

Evidencia-se ainda como resultado positivo desta experiência o interesse das escolas em participar das novas edições do Desafio. Inclusive outras escolas da cidade e região entraram em contato e demonstraram interesse das alunas em participar. Isso demonstra a boa repercussão da experiência nos espaços escolares.

\section{Considerações Finais e Direcionamentos Futuros}

Observa-se que diante de uma cultura digital torna-se inevitável o impacto da tecnologia na área educacional. $\mathrm{O}$ uso das ferramentas computacionais, de forma lúdica propicia flexibilidade e criatividade fazendo o aluno explorar, pesquisar, encorajando o pensamento criativo, ampliando o universo, saciando a curiosidade, alimentando a imaginação e estimulando a intuição, e tudo isso contribui para o aprendizado.

As atividades que foram propostas visam aproximar meninas/mulheres do universo do desenvolvimento tecnológico e encorajá-las a seguirem carreira nesta área, evidenciando o potencial criativo, a competência, a inteligência e as habilidades que as meninas possuem para produzir tecnologias e não apenas para utiliza-las.

Para tanto foram propostas ações com vistas a proporcionar a alunas de ensino médio um primeiro contato prazeroso com noções de lógica de programação, de forma que elas percebam que programar pode ser algo estimulante e possível, não tão difícil quanto elas imaginavam. Também procurou-se possibilitar uma maior aproximação com o computador como instrumento de trabalho e noções básicas de funcionamento de smartphones estimulando-as a criar aplicativos de sua livre escolha para um dispositivo amplamente adotado pelo público em geral.

Há muito ainda a ser feito. A necessidade de despertar o interesse dos estudantes desde cedo pelas ciências e em especial pela Ciência da Computação torna-se necessidade premente. Por fim, considera-se o Desafio de Programação uma iniciativa em processo de desenvolvimento e inovação que, contudo, já conta com resultados de sucesso, considerando os resultados obtidos na $1^{\text {a }}$ Edição, e um novo olhar da comunidade envolvida em relação ao tema Mulheres em TI. 
VI Congresso Brasileiro de Informática na Educação (CBIE 2017)

Anais do XXIII Workshop de Informática na Escola (WIE 2017)

Visto que a metodologia constituída nesta experiência apresentou resultados positivos, a mesma está sendo empregada na organização da $2^{\mathrm{a}}$ edição do Desafio de Programação, cujo o foco é o desenvolvimento de jogos fazendo uso da ferramenta Construct 2.

\section{Referências Bibliográficas}

BARCELOS, T.; SILVEIRA, I. F. "Pensamento Computacional e Educação Matemática: Relações para o Ensino de Computação na Educação Básica”. In: XX Workshop sobre Educação em Computação, 2012, Curitiba. Anais do XXXII CSBC, 2012.

DE FRANÇA, Rozelma Soares; DA SILVA, Waldir Cosmo; DO AMARAL, Haroldo José Costa. Despertando o interesse pela ciência da computação: Práticas na educação básica. In: Proceedings of International Conference on Engineering and Computer Education. 2013. p. 282-286.

DUTRA, S.; ELIAS, C.; DAL'LGNA, M.C. FABRIS, E.; SARAIVA, K. O conceito de competência e seus desdobramentos didático-pedagógicos. Disponível em: http://unisinos.br//formacao-docente/2015/01/Ensino-por-competencias-naUnisinos.pdf. Acesso em 2/2/2017.

GOMES, Wesckley Faria, et al. "Incentivando meninas do ensino médio à área de Ciência da Computação usando o Scratch como ferramenta." In: Anais do Workshop de Informática na Escola (CBIE). Vol. 20. No. 1. 2014.

LIMA, Michelle Pinto. As mulheres na Ciência da Computação. Estudos Feministas, Florianópolis, 21(3): 496, setembro-dezembro, 2013.

MACIEL, C; BIM, S. A. (2016) Programa Meninas Digitais - Ações para divulgar a Computação para meninas do ensino médio. In: Anais do Computer on the Beach 2016, Florianópolis, SC. pp.327-336, 2016.

RAMOS, Nadja et al. Ensino de programação para alunas de ensino médio: Relato de uma experiência. In: XXIII Anais do Workshop sobre Educação em Computação. 2015.

SANTOS, Elisângela Ribas et al. Estímulo ao Pensamento Computacional a partir da Computação Desplugada: uma proposta para Educação Infantil/Stimulus to computational thinking: a proposal for elementary school. Revista Latinoamericana de Tecnología Educativa-RELATEC, v. 15, n. 3, p. 99-112, 2016. 